\title{
A Python Computer Science Course Taught with a New Web Platform
}

\author{
Francis B. Lavoie ${ }^{l}$, Pierre Proulx ${ }^{l}$ \\ ${ }^{1}$ Département de génie chimique et de génie biotechnologique, Université de Sherbrooke \\ Francis.B.Lavoie@USherbrooke.ca
}

Computer science is now considered as the basis of the future economy [1]. It is then important to adapt courses given to future engineers to this reality. All Canadian engineers now require a solid basis in computer science and, especially, they need to be aware of and able to use computer tools specific to their domain. Consequently, the Department of Chemical Engineering of the Université de Sherbrooke switched from Matlab teaching to Python with the Spyder programming interface in 2016. This latter high-level programming language is indeed free and open-source and, particularly, its use is constantly increasing in both research and industrial fields [2].

From this switch, the teaching method was also thoroughly revised. Courses are now given in video format accessible via Catalyseur.ca. This interactive and user-friendly interface was completely created from scratch in our department. The platform has several interesting features. Amongst others, Catalyseur.ca allows students to watch the courses and to ask questions to the professor or to their colleagues about their contents on the same webpage. Courses are also linked to exercises to resolve. These exercises were all created from professors and graduate students in our department. Around the half of them are related to chemical engineering typical cases.

Catalyseur.ca has other didactic features which are not yet available in common learning management systems such as Moodle. Students can follow their progress with graphics that are automatically updated after the completion of a course or an exercise. This feature also generates statistics for the professor to help her or him targeting concepts or exercises which may be generally less understood by the class. Students can also directly write and run their Python script to solve a problem on each exercise webpage.

The Catalyseur.ca platform and the switch from Matlab to Python allowed to teach more computer science notions while keeping the same course difficulty. For example, Python modules specialized in fluid and thermodynamic properties are now implemented into the course and are required to complete the projects proposed at the end of the semester.

All course periods are now dedicated to individual help to students. The course format was particularly appreciated by students with learning difficulties who could watch or pause the courses any number of times. This first-semester course then provides a strong basis for the 7 following semesters to all students. Considering their high level of knowledge in computer science, problems to solve in other courses can now be complexified by solving them with computer tools.

[1] MAISONNEUVE Vincent, Pénurie d'informaticien et pas seulement en informatique, Radio-Canada.ca, 23 nov. 2017

[2] IEEE Spectrum, The 2017 Top Programming Language, 18 jul. 2017

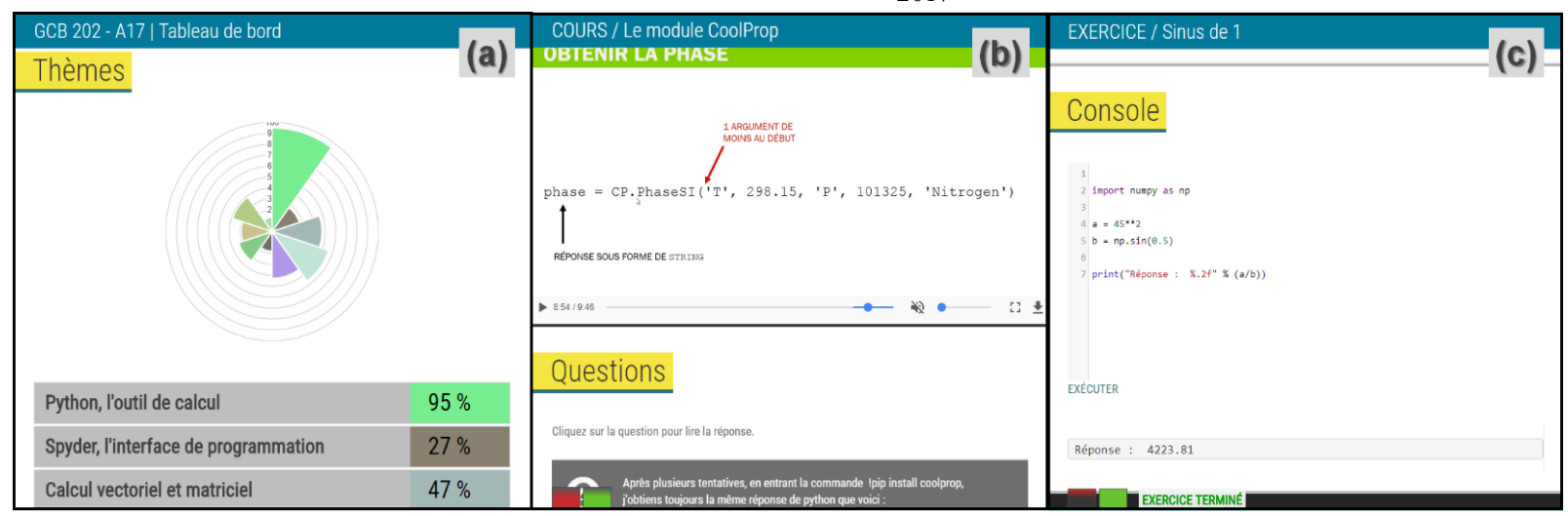

(a) Progress graphics are automatically generated for each student on the course main page. (b) Notions are taught with videos. Students are invited to ask additional questions or to read answers to questions asked by their colleagues just below each video. (c) More than 150 original exercises were written in our department. Students can code the solutions directly on the Catalyseur.ca website. 